\title{
Gestão do conhecimento e a visão cognitiva dos repositórios institucionais
}

Gleisy Regina Bories Fachin

Doutoranda do Programa de Pós-Graduação em Engenharia e Gestão do Conhecimento da UFSC.Mestre em Engenharia de Produção, UFSC. Professora do Departamento de Ciência da Informação da UFSC.

Jaqueline Stumm

Doutoranda do Programa de Pós-Graduação em Engenharia e Gestão do Conhecimento da UFSC. Mestre em Ciências da Computação pela UFSC. Professora da Faculdade de Santa Catarina e do Instituto de Ensino Superior da Grande Florianópolis

Rafaela Lunardi Comarella

Mestre em Engenharia e Gestão do Conhecimento da UFSC. Colaboradora da UFSC, área de Ciência da Computação: Simulação de Sistemas e Educação a Distância.

Francisco A.P. Fialho

Doutor em Engenharia de Produção, eEngenharia do Conhecimento pela UFSC. Professor Associado da UFSC.

Neri Santos

Doutor em Ergonomie de l'Ingenierie e PHD em Ingenierie Cognitive. Professor Titular do Departamento de Engenharia do Conhecimento na UFSC.

Este artigo objetiva apresentar um estudo sobre os repositórios institucionais, sua relação com a gestão do conhecimento e com a visão cognitiva na formação dos mesmos. Apresenta um esquema da comunicação cognitiva entre usuários e os repositórios institucionais.

Palavras-chave: Repositórios institucionais; Gestão do conhecimento; Visão cognitiva. 


\title{
Management of the knowledge and vision cognitiva of the institucional repositories
}

\begin{abstract}
This objective article to present a study on the institucional repositories and its relation with the management of the knowledge and the cognitiva vision in the institucional formation of the same ones, presenting a project of the cognitiva communication between users and repositories.
\end{abstract}

Keywords: Institucional repositories; Management of the knowledge; Cognitive vision.

Recebido 02.01.2008 em Aceito em 24.07.2009

\section{Introdução}

O surgimento da sociedade do conhecimento ocasionou mudanças que alteraram as formas de produção de bens e serviços (DIB; SILVA, 2006). O compartilhamento de dados e informações, visando a geração de novos conhecimentos é a temática do momento.

As universidades, os museus, os governos e outras organizações abrigam os tesouros que foram escondidos nos arquivos, nos porões, nos sótãos, em formatos de cópia, e em uma variedade de dispositivos de armazenamento. Estes tesouros abrangem os materiais científicos, tecnológicos, culturais, artísticos e históricos geralmente indisponíveis para os pesquisadores e o público (BRANIN, 2004; DRAKE, 2004).

De fato, na maioria dos países a produção do conhecimento científico ocorre principalmente nas universidades, ressaltando-as como protagonistas no cenário de produção do conhecimento (LEITE; COSTA, 2006). Este mesmo aspecto é observado por Alberts (2002), quando afirma que a informação científica e técnica é um bem público global, e que a pesquisa deve ser facilmente acessada, além de estar disponível livremente para $o$ benefício de todos e para $o$ aceleramento do crescimento científico.

A iniciativa de Arquivos Abertos e o Movimento de Acesso Aberto à Informação Científica vêm propondo que a informação científica seja disponibilizada gratuitamente; o que é favorecido pelos avanços constantes das tecnologias de informação e comunicação (TIC) dos últimos anos, gerando uma demanda do uso da web para a disseminação dos resultados de pesquisas.

A disponibilização das informações tem seu sentido na busca das mesmas por pesquisadores, cientistas, professores, alunos e a população em geral. E é nesse contexto que o papel de modelos alternativos de 
comunicação científica, tais como portais em bibliotecas digitais e, recentemente, repositórios digitais, temáticos ou institucionais, vem crescendo claramente.

O repositório temático diz respeito à produção intelectual de uma determinada área do conhecimento; já o repositório institucional é voltado para o armazenamento, preservação e disseminação da produção intelectual de uma instituição ou de um grupo de instituições que resolvem trabalhar de forma cooperativa.

Os repositórios institucionais, com a implementação mais comum de sistemas de arquivos abertos (open access), segundo Reenen (2006), têm sido discutidos na literatura sob vários aspectos, tanto como uma ferramenta quanto como uma estratégia para maximizar a visibilidade da pesquisa de uma universidade ou instituição. Sob o aspecto de ferramenta de gestão do conhecimento, eles podem potencializar a troca de conhecimento no seio das comunidades científicas, em seus diferentes níveis de agregação que, por outro lado, alimentam a preocupação com o acesso à pesquisa e com os impactos causados pelo acesso livre ao conhecimento gerado por pesquisadores de todas as áreas do conhecimento.

Os repositórios institucionais, parafraseando Drake (2004), estão sendo criados para controlar, preservar e manter os recursos digitais, permitindo uma recuperação eficaz; da mesma forma que serve de arquivo para a história das instituições.

Assim, o presente artigo visa contribui para a discussão sobre os Repositórios Institucionais, sua relação com a gestão do conhecimento e a visão cognitiva no tratamento das informações disponibilizadas.

\section{Repositórios institucionais}

Os primeiros repositórios surgiram da necessidade do homem de armazenar suas informações, e para isso utilizavam museus, bibliotecas e arquivos. No artigo "O advento da nova organização", de 1988, Peter Drucker declara que o conhecimento da organização é o seu recurso mais importante, e que gerenciar esse recurso é assegurar o conhecimento do que já foi produzido e as novas aplicações que se criam. A partir disso, ocorre o movimento de gerenciamento do conhecimento.

A facilidade em criar e disseminar conteúdo ganhou força em 2000, desafiando as universidades a coordenar, compartilhar e preservar seus dados digitais. Em 2002, o Instituto de Tecnologia de Massachusetts (MTI), em colaboração com a Hewlett-Packard, lançou um repositório institucional de livre acesso, o que representou uma nova estratégia para o gerenciamento do conhecimento produzido pelas universidades (MCLENDON, 2005).

Os repositórios institucionais ganharam força devido ao movimento de acesso aberto, que gerou mudança na indústria de publicação científica. Desde suas primeiras implementações, os repositórios têm sido voltados para a informação científica. Assim, os repositórios institucionais 
podem preservar e possibilitar o acesso ao material não publicado oficialmente, por um veículo reconhecido, de uma universidade, muitas vezes como alternativa aos custos elevados de uma publicação tradicional, contribuindo para o prestígio desta mesma universidade (BAILEY, 2005).

Ainda nessa perspectiva, Leite (2006, p.88) afirma que os repositórios,

além de expandir o acesso à pesquisa, reafirmar o controle sobre o saber pela academia, reduzir o monopólio dos periódicos científicos, entre outras mudanças significativas no sistema de comunicação científica, têm o potencial de servir como indicadores tangíveis da qualidade de uma universidade e de demonstrar a relevância científica, social e econômica de suas atividades de pesquisas, aumentando a visibilidade, 0 status e o valor público da instituição.

Segundo Costa e Leite (2006), os repositórios institucionais são sistemas de informação que servem para armazenar, preservar e difundir os resultados de pesquisa e desenvolvimento de uma determinada instituição e/ou de um determinado grupo de instituições, e são mantidos de forma individualizada ou por grupos de instituições que trabalham de forma cooperativa.

Ainda para Costa e Leite (2006), quem pode publicar nestes repositórios institucionais são os autores interessados, os quais já podem ter publicado seu trabalho em revistas de acesso livre ou em revistas comerciais habituais, fazendo o "auto-arquivo" no repositório da sua instituição. Estes repositórios contribuem para o aumento da visibilidade da instituição e para a preservação da sua memória intelectual.

$\mathrm{Na}$ opinião de Lynch (2003), os repositórios institucionais desenvolvidos pelas universidades são considerados "um conjunto de serviços que a universidade oferece aos membros de sua comunidade, visando o gerenciamento e a disseminação dos materiais (informações) digitais criados pela instituição e pelos membros de sua comunidade".

Partindo destes pressupostos, Costa e Leite (2006) discutem o papel que os repositórios institucionais assumem de fato em relação a duas questões fundamentais: a primeira, na melhoria do ensino, do aprendizado e da pesquisa, ou seja, na melhoria do saber e da comunicação científica. E em segundo lugar, no potencial que encerram como instrumentos de gestão do conhecimento produzido, disseminado e utilizado nas e pelas universidades.

Os repositórios institucionais podem conter uma diversidade de material digital, dependendo do objetivo estabelecido pela instituição. Bailey (2005) evidencia essa diversidade ressaltando que os repositórios institucionais podem receber uma variedade de material produzido por estudantes de diversas áreas, como documentos eletrônicos, relatórios técnicos, teses, dissertações e material didático. Johnson (2002) acrescenta os portfólios eletrônicos, relatórios anuais da instituição, 
gravações de vídeos, programas de computador, fotografias e trabalhos de arte; ou seja, qualquer material digital que essa instituição deseja preservar, produzido por estudantes, pelo corpo docente ou por pesquisadores.

Reenen (2006) identifica dois objetivos principais com a manutenção de um repositório institucional:

1. promover acesso livre (open access) para pesquisa institucional através do arquivamento livre (self-archiving);

2. armazenar e preservar recursos institucionais digitais, incluindo não publicações ou literatura facilmente perdida (ex: teses e relatórios técnicos).

Dentre todas as características citadas, percebe-se o potencial dos repositórios institucionais na mudança do sistema de comunicação científica. Inicialmente proporciona uma criticidade ao componente do sistema de comunicação científica, melhorando o acesso à pesquisa, reafirmando o controle sobre o conhecimento, aumentando a competição e reduzindo o monopólio em relação aos periódicos. Além disso, pode servir como um potencial indicativo de qualidade de uma universidade, demonstrando a relevância científica, social e econômica de suas pesquisas, aumentado a visibilidade, o status e 0 valor público da instituição (BAILEY, 2005).

Indo ao encontro dessas considerações, Rodrigues (2007) define repositórios institucionais como sistemas de informação que armazenam, preservam, divulgam e dão acesso à produção intelectual de comunidades universitárias e/ou de um grupo específico de instituições ou pessoas. Estes repositórios intervêm em duas questões estratégicas: contribuem para o aumento da visibilidade e do valor público das instituições, servindo como indicador tangível da sua qualidade, e contribuem para a reforma do sistema de comunicação científica, expandindo o acesso aos resultados da investigação e reassumindo o controle acadêmico sobre a publicação científica.

Os repositórios constituem uma manifestação evidente da importância emergente da gestão do conhecimento no contexto da educação superior. Com base na similaridade e na complementaridade existente entre os processos do sistema de comunicação científica e as atividades de gestão do conhecimento, os repositórios institucionais constituem uma poderosa alternativa tanto para a comunicação quanto para a gestão do conhecimento científico (LEITE, 2006).

Complementando, os repositórios institucionais, sejam universitários e/ou de instituições de pesquisas, ou ainda particulares, representam um avanço tecnológico em prol da disseminação da comunicação científica e do livre acesso a todos. A solução ideal para esse avanço é a aliança entre uma organização capacitada em gerenciar dados digitais e os criadores desses dados, gerando, dessa forma, conhecimento sobre o material, contribuindo para decisões de preservação de conteúdo e de intervalos dessa atividade (LEITE; COSTA, 2006). Evidencia-se aqui a necessidade 
de políticas de gerenciamento desses repositórios, reconhecendo-os como vitais para a instituição.

\section{Gestão do conhecimento}

A gestão do conhecimento tem sido apontada por estudiosos, pesquisadores e cientistas como relevante, sendo uma intervenção necessária e obrigatória ao crescimento das organizações, nas mais variadas áreas de atuação. Assim, com o impacto das grandes transformações no cenário empresarial, a necessidade das organizações de aprenderem a fazer a gestão da informação torna-se um diferenciador para o sucesso, indicando que as elas têm reconhecido a rápida obsolescência do conhecimento e a necessidade de não só assimilarem, mas também de gerarem novos conhecimentos.

A gestão do conhecimento (Knowledge Management - $K M$ ) se transforma em um valioso recurso estratégico para a vida das pessoas e das empresas. O conhecimento sempre desempenhou e desempenha papel fundamental na evolução do mundo, das empresas e das pessoas. Sua aquisição, aplicação, armazenagem e recuperação sempre representaram estímulo para as conquistas no decorrer dos tempos, na evolução dos seres humanos. Assim, o saber sobre determinada ação ou fato, ou até sobre determinada coisa, não proporciona, por si só, maior poder de competição para uma organização - só será real e significativa se aliado, gerido e aplicado.

A criação e a implantação de processos que gerem, armazenem, gerenciem e disseminem o conhecimento representam o mais novo desafio a ser enfrentado pelas empresas - e aqui aparecem os repositórios institucionais como uma das inúmeras soluções às organizações.

O conceito de gestão do conhecimento parte da premissa de que todo o conhecimento existente em uma determinada organização, na cabeça das pessoas, nos processos diários e plenamente ativos, nos inúmeros setores, salas e chefias, é o que forma as empresas. E é através desta junção de saberes que as empresas progridem, evoluem e se tornam referência. Aplicar uma gestão do conhecimento é formar um ciclo de troca constante de saberes entre todos os envolvidos, tornando a empresa mais eficiente e forte diante da concorrência.

Nesta linha inúmeros autores, conforme citados por Leitão (2006), entre eles: Nonaka e Takeuchi (1997), Sveiby (1998), Davenport e Prusak (1998), Kanter (1999), Eboli (1999), Cavalcanti, Gomes e Pereira (2001) e Yang (2004), colocam que a gestão do conhecimento traz uma nova luz sobre como uma organização pode ganhar vantagem competitiva e tornar-se inovadora com sucesso.

Na opinião de Del Tio (2006), essa técnica hoje chamada de "gestão do conhecimento" contribui para o envolvimento de todas as pessoas dentro de uma organização ou empresa, unificando as participações ativas 
e de opiniões, potencializando os resultados obtidos e a eficácia da organização.

Falar sobre gestão do conhecimento requer entender este novo campo do conhecimento Davenport e Marchand (2004) apresentam um levantamento histórico do surgimento deste segmento, hoje chamado de gestão do conhecimento e que, para muitos pesquisadores, cientistas ou até empresários parece apenas uma expressão nova para os famosos "sistemas de informações", discordando de outros autores e/ou empresários.

A gestão do conhecimento já existia há muitos anos. Ela foi surgindo como uma conseqüência natural da evolução dos tempos, da soma de sistemas de informações e tecnologias de informação e comunicação (TIC), da evolução das redes e da própria globalização e popularização da Internet. Considerando-se que as organizações já utilizavam computadores há mais de 40 anos, a informação era contida em registros e documentos impressos e, aos poucos, passaram a ser automatizadas armazenadas em banco de dados (DAVENPORT; MARCHAND, 2004). Posteriormente, os dados eram recuperados como informações, assimilados por alguém e transformados em conhecimento, sendo, posteriormente, transformados em informações a outras pessoas, formando um ciclo evolutivo de criação de novos saberes.

No período de 1970-1990 ocorreu a evolução tecnológica dos computadores, somada às redes e aos softwares. Cada vez mais, tudo se moderniza e as necessidades de concorrência entre empresas impulsionaram a passagem do simples processamento de dados à adoção de sistemas de informações mais complexos, acompanhados da gestão de documentos - a necessidade de garantir a migração do formato impresso para o formato digital, assegurando a preservação dos dados. Ocorre um incremento em sistemas de informação; uma abertura na discussão sobre direitos autorais, conservação e preservação da informação digital; a explosão da comunicação científica no formato on-line; aparecem os primeiros portais, bibliotecas digitais e repositórios. Conforme se observa nas afirmações de Davenport e Marchand (2004, p. 189), nem "bem as pessoas e organizações haviam aprendido a lidar com os dados e os gestores já começaram a buscar a gestão da informação. Subitamente, quando todos começavam a dominá-la, surgiu a gestão do conhecimento". Os mesmos autores argumentam que existem grandes componentes da gestão da informação que formam a base da gestão do conhecimento, e que muita coisa que se faz em CG é, na verdade, gestão da informação.

O dia a dia atual dos seres humanos é uma contribuição constante, movendo dados e informações, e gerando conhecimento. Estes três elementos são largamente discutidos na literatura e, principalmente, na academia. Baseando-se em Davenport e Marchand (2004), os dados conteúdo que tem pouco valor em si mesmo - são fáceis de manipular e armazenar em banco de dados; as informações são os dados interpretados, contextualizados e assimilados por alguém; e o conhecimento é a informação que está dentro da mente das pessoas. É 
valioso porque os seres humanos criam novas idéias, percepções e interpretações, e as aplicam em inovações. É comum que as interpretações de dados, informação e conhecimento se interponham, se completem e se reafirmem e, em muitos casos, fica difícil saber onde termina um e começa o outro.

Em pesquisa realizada em 1996, Davenport e Marchand (2004) identificaram empresas que implantaram a gestão de conhecimento. Nos resultados, constataram que $80 \%$ delas criaram algum tipo de repositório, contendo informações gerais em seu campo de atuação. Esses conjuntos de informações, agrupados e de certa forma organizados, poderiam ser identificados como repositórios de "informações sobre conhecimento". Ou seja, estes conjuntos levavam as pessoas a encontrar, recuperar e processar dados e/ou informações, facilitando a geração de conhecimento.

O conhecimento em si está nas pessoas, intrínseco a elas, e é no dia a dia de uma organização que se forma um ciclo constante de troca, onde uma pessoa transforma seu conhecimento em informação, registrando-a e divulgando-a, da mesma forma que assimila outras, criando um ciclo de compartilhamento evolutivo, onde dados, informação e conhecimento são trocados. E aí entra a gestão de informação, que trabalha na unificação e consolidação deste processo de criação de conhecimento - promove o gerenciamento deste ciclo, revertendo-o em prol da evolução eficiente de uma determinada organização e/ou empresa.

Muitos exemplos são encontrados na literatura, em destaque as empresas orientais do Japão, Coréia, China e de outros países, que se voltam ao conhecimento tácito, inato a seus trabalhadores. Já as empresas ocidentais voltam-se ao trabalho unificado, envolvendo toda a empresa, onde todos devem assumir o papel de criadores do conhecimento, promovendo uma espiral crescente de envolvimento, onde todos passam a assumir seus papéis em prol do desenvolvimento eficiente e lucrativo (DAVENPORT; MARCHAND, 2004).

Percebe-se que a grande maioria das organizações aplica ou afirma que usa a gestão do conhecimento, utilizando repositórios como recurso para disponibilizar informações e gerar conhecimento; mas, é necessário que isso seja gerenciado e incorporado por todos os membros da organização, que as ações implementadas atinjam todos os níveis da empresa e que por eles sejam incorporados e assimilados.

Neste aspecto, percebe-se que "assimilar a gestão do conhecimento" tem dois aspectos distintos: a cultura e o trabalhar o conhecimento. Não adianta implantar uma gestão do conhecimento em uma empresa se todos ou alguns trabalhadores não souberem o que é, ou se não forem treinados para esta nova visão, ou, ainda, se não aceitarem usar ou partilhar deste processo. Assim, mesmo o melhor dos repositórios, estruturado e disponibilizado para o uso dentro de uma empresa, simplesmente não será acessado, usado, consultado. A utilização e o pleno uso pelas pessoas só ocorrerá se as mesmas estiverem treinadas, incentivadas e cientes de que sua participação no processo é fundamental. Pois, aplicar uma GC é a soma da gestão de 
pessoas com a gestão de informação, acrescida das tecnologias de informação e comunicação. Apenas essa junção e a plena aceitação de todos os elementos envolvidos podem gerar, com eficiência, a gestão de informação.

Para a implementação da gestão de informação, a literatura apresenta inúmeros estudos, modelos e ações, pois se trata de um assunto em pleno desenvolvimento e incorporação. Em sua dissertação de mestrado, Carvalho (2005) cita uma relação de sete modelos para a implantação de gestão de informação em organizações e seus respectivos autores e ano, a saber:

1. Três pilares do GC, de Wiig (1993), adaptado por Holsaple e Joshi (1999);

2. Núcleos de capacidade e atividades de construção do conhecimento de Leonard-Borton (1995), adaptado por Holsaple e Joshi (1999);

3. Modelo de gerenciamento organizacional de Arthur Andersen e Americam Productivi and Quality Center (APQC) (1996), adaptado por Holsaple e Joshi (1999);

4. Modelo de organização do conhecimento de Choo (1996), adaptado por Holsaple e Joshi (1999);

5. Estrutura de GC, de Spek e Spijkervet (1997), adaptado por Holsaple e Joshi (1999);

6. Principais atividades de GC, proposto por Holsaple e Joshi (2002);

7. Modelo de GC, de Wenger, McDermott e Snyder (2002).

Carvalho (2005) destaca o uso das Comunidades de Prática como uma das possíveis soluções às implantações de GC em organizações. Também outros autores, como Lawrence (2003), opinam a favor dos repositórios institucionais, os quais se caracterizam "como uma manifestação visível da importância emergente da gestão do conhecimento na educação superior". Ainda Carvalho (2005) prevê em seus estudos que, a longo prazo, é provável que "o impacto dos repositórios institucionais mude muitas das suposições a respeito de como a produção intelectual é gerida por indivíduos, seus colegas e a academia, além de como a própria pesquisa é conduzida". Sua implantação em organizações acadêmicas ou em empresas de cunho produtivo é, sem dúvida, uma solução a implantações de GC eficazes. Para que isso ocorra, a análise detalhada da organização que irá implantar a gestão do conhecimento é necessária, e isso requer uma tomada de decisão que, na visão de Choo (2006), é a ação provocada por uma situação em que é preciso fazer uma escolha, implicando em identificar e avaliar as alternativas e suas conseqüências.

Assim, fazendo associação ao uso de repositórios, dando ênfase aos repositórios institucionais, destacamos quatro dimensões necessárias para mapear e implantar uma GC eficaz em uma organização que, obrigatoriamente, tem que envolver todas as partes: 0 indivíduo, 0 
grupo/setor/direção e a organização como um todo. São eles o processo, o tipo, o nível e o contexto, os quais, aplicados, criam um mapa que demonstra o conhecimento tácito e o explícito e toda a estrutura organizacional (SVEIBY, 1998; DAVENPORT; MARCHAND, 2004).

Quando se tem uma visão de toda a organização, depois de discutido cada ponto identificado, passa-se à escolha de soluções, onde entra a tecnologia de ponta, com soluções de software que possam agilizar o compartilhamento de conhecimento entre todos os funcionários da organização. A criação de repositórios institucionais, portais de conhecimento, comunidades de prática, bancos de talentos e ferramentas para inteligência competitiva são apenas alguns exemplos de soluções que podem ser implantadas.

\section{Repositórios institucionais frente à visão cognitiva}

Lidar com uma grande quantidade de informação é um enorme desafio nas mais diversas áreas. Por volta dos anos 70, os estudiosos passaram a dar maior importância à visão do indivíduo (usuário) perante a utilização dos sistemas e da informação, objetivando facilitar a gestão do conhecimento. Para tanto, buscou-se a contribuição das ciências cognitivas, entre outras, a fim de investigar o comportamento dos usuários diante das atividades que envolvem o tratamento das informações, sua disponibilização, o armazenamento e a recuperação.

A palavra cognição tem origem nos escritos de Platão e Aristóteles. É traduzida como o ato ou processo de conhecer, que envolve atenção, percepção, memória, raciocínio, juízo, imaginação, pensamento e linguagem. Neste aspecto, Fialho (2007, p. 34) coloca que a cognição "é um termo usado em psicologia e áreas afins ligado ao aprendizado e utilizado para fazer referências à memória, associações, linguagens e soluções de problemas". Para alguns investigadores, ela inclui os processos de atenção e a representação consciente. Ainda considerando Fialho (2007, p. 44), "o fenômeno da cognição pode ser explicado como sendo: primeiro uma função biológica, segundo, como um processo pedagógico e, por último, por uma episteme". Ainda citando o autor acima (2007, p. 44), "Piaget nos ensina que cognição e emoção são faces de uma mesma moeda". Em outras palavras, a cognição tende a estar em algum lugar entre áreas tradicionalmente chamadas de percepção e aprendizado e/ou incorpora elementos de ambos, o que dificulta sua plena assimilação dentro das tecnologias.

Pela visão cognitiva, podemos descrever o funcionamento do cérebro humano diante da informação da seguinte forma: primeiramente a informação existe no mundo real, estando intrínseca nas propriedades dos objetos, bastando ser captada pelos nossos sentidos e percepções. Após esta coleta, as informações são representadas através de símbolos que são armazenados nas memórias primária ou secundária, e são posteriormente processadas, geralmente alterando 0 estado de conhecimento do sujeito. O processo se encerra através da geração de 
uma saída na forma de uma ação no mundo, ou da realimentação do conhecimento do usuário.

Cabe destacar que são inúmeros os trabalhos, pesquisas e pessoas envolvidas com o estudo das diversas visões e teorias cognitivas aplicadas à gestão do conhecimento, à engenharia, à tecnologia de informação e no dia a dia das pessoas.

Nesta perspectiva, deve-se colocar o individuo como agente ativo na construção do significado das situações com as quais se depara na utilização dos repositórios institucionais. Ou seja, o usuário deixa de ser considerado um receptor passivo da informação, passando a ativo, onde o seu conhecimento e seu modelo mental terão uma integração na interação com a estrutura de informação.

Segundo Neves (2006, p. 41):

a abordagem do processamento da informação pesquisa a compreensão textual, conceituada como uma atividade cognitiva que envolve percepção, memória, inferência e dedução. A compreensão do texto ocorre a partir do conhecimento de mundo e da familiaridade com os diversos tipos de textos, requerendo consciência semântica e pragmática de leitores mais proficientes.

Quando se analisa a organização das informações em uma determinada fonte, nesse estudo os repositórios institucionais, percebe-se que em qualquer sistema de informação não é só a recuperação de informações que envolve aspectos cognitivos, mas, sim, outros processos como a indexação que, segundo Neves (2006), diz respeito a um processo intelectual que tem por base a compreensão do texto e a representação do documento. Este processo está intimamente ligado à abordagem do processamento da informação na psicologia cognitiva.

Dessa forma, a visão cognitiva se faz necessária na estruturação de repositórios, visto que os mesmos abordam uma variedade de informações e de usuários. Neste contexto, a compreensão textual, a geração de texto (tradução para a linguagem de indexação e/ou resumo) e a representação do conteúdo (criação de linguagens de indexação) devem ser evidenciadas (NEVES, 2006).

A partir das reflexões empreendidas para o desenvolvimento do presente artigo, baseando-se nos trabalhos de Ingwersen (1992) e no esquema da arquitetura cognitiva de Richard (1998), citado por Fialho (2007), adapta-se, em um primeiro estudo, um esquema de estruturação de repositórios institucionais que visem atender os processos cognitivos dos indivíduos que irão interagir com este ambiente na busca por informação. A figura 1 representa uma proposta de estruturação de repositórios institucionais sob uma visão cognitiva.

Quando o usuário busca informação em um repositório institucional, diversos fatores irão interferir neste processo, entre eles os seus conhecimentos conceituais, os conhecimentos conceituais implícitos no 
repositório (linguagens documentais e políticas adotadas) e a forma de representação do documento.

Diante da análise da utilização de repositórios institucionais por usuários, percebe-se claramente o processo cognitivo nas fases de categorização, indexação e recuperação de informação.

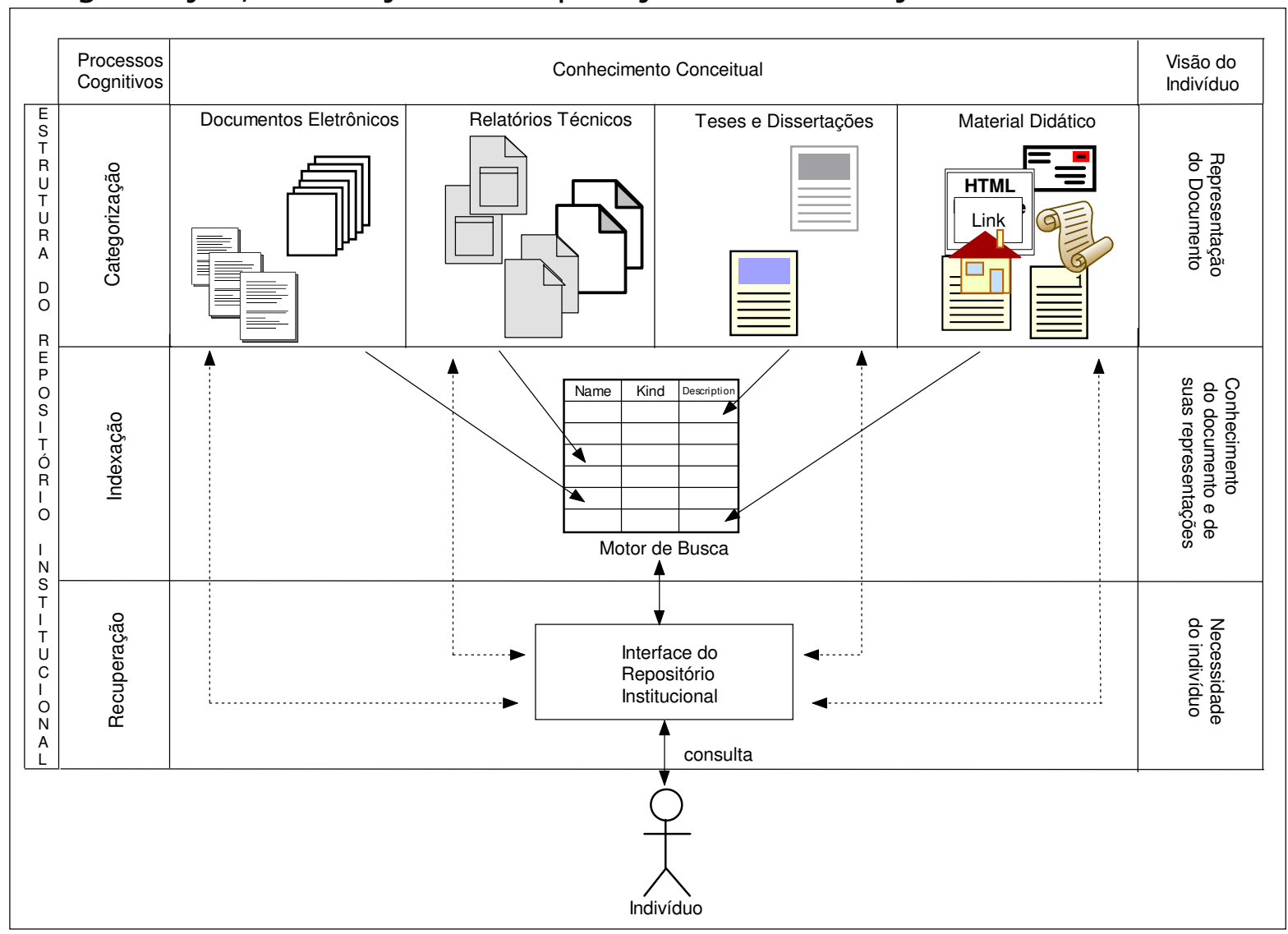

FIGURA 1 - Estrutura do Repositório Institucional sob uma visão cognitiva

Fonte: Adaptado pelos autores de INGWERSEN (1992) e RICHARD (1998), citado por FIALHO (2007).

Entende-se por categorização a faculdade mental do indivíduo utilizada ao organizar os conceitos que compõem um campo de conhecimento. Dessa forma, ao interagir com o mundo, o indivíduo reconhece similaridades e diferenças em relação aos conceitos, construindo novos conhecimentos com base nas relações percebidas entre eles.

Jacob e Shaw (1998, p. 155), citados por Lima (2003, p. 82), definem categorização como "um processo cognitivo de dividir as experiências do mundo em grupos de entidades ou categorias, para construir uma ordem física e social do mundo". Esta divisão simplifica a interação do indivíduo com o ambiente, por facilitar o armazenamento e a recuperação da informação, e por reduzir a demanda da memória humana.

A indexação envolve atividades cognitivas na compreensão e na representação do documento. Possibilita o entendimento de como a 
estrutura do sistema de informação afeta a interação entre a análise do documento, a representação do conteúdo e a recuperação.

Já a recuperação de informação envolve as estruturas de conhecimento do usuário, do documento, do indexador, e a representação do conhecimento adaptado para o documento (LIMA, 2003).

Percebe-se que, conceitualmente, o processamento da informação está centrado no conhecimento baseado no modelo de mundo do usuário, seja na categorização, indexação ou recuperação da informação (BORGES et al., 2003, 2007). A informação é associada ao contexto e à maneira que cada indivíduo vê o mundo, consistindo no somatório de diferentes estruturas de conhecimento, onde todo estágio cognitivo implica num contexto, que é organizado pelo sistema conceitual da informação.

A partir do que foi abordado, reforça-se a importância dos repositórios institucionais utilizarem a visão cognitiva na concepção de sua estrutura, como forma de prover uma estrutura padronizada que permita eficiência na interação dos indivíduos com este sistema e eficácia na recuperação das informações solicitadas.

\section{Considerações finais}

Constata-se que os repositórios institucionais são um dos recursos mais viáveis, confiáveis e eficazes para a implantação de gestão do conhecimento em qualquer organização; principalmente quando enriquecido pelas técnicas da ciência da cognição, além das mais recentes ferramentas de tecnologia de informação e comunicação.

A gestão do conhecimento é baseada em áreas multidisciplinares, de forma que implantar técnicas de gestão requer a interação entre a gestão de pessoas e de informação, incorporada às tecnologias de informação e comunicação, o que proporcionaria um resultado eficiente, atendendo a uma demanda de usuários cada dia mais exigentes e necessitados de informações reais, concretas e em tempo real.

Neste estudo percebeu-se, também, a importância da visão cognitiva para o aperfeiçoamento da recuperação de informação em repositórios institucionais, bem como para a sua implementação; pois a cada dia cresce o número de usuários, de necessidades de informações com qualidade e disponíveis de forma rápida e precisa.

É certo que muito se tem a fazer, estudar, aperfeiçoar para o pleno uso dos repositórios institucionais como ferramenta para a gestão do conhecimento. Mas, com certeza, muito já se avançou e muitos exemplos, em plena operação, encontram-se no mercado.

Cabe destacar, entretanto, que a construção de repositórios institucionais requer a adoção de políticas, normas e padrões, além do que, preferencialmente, as informações depositadas devem ser revisadas por seus pares. 


\section{Referências}

ALBERTS, B. Engaging in a worldwide transformation: our responsibility as scientists for the provision of global public goods. President's Address to the Fellows of the National Academy of Sciences. USA; Washington D.C.: [s. n.], 2002.

BAILEY, C. W. Jr. Open access bibliography: liberating scholarly literature with e-prints and open access journals. Washington, DC: Association of Research Libraries, 2005. p. 18. Disponível em: <http://www.escholarlypub.com/oab/oab.htm>. Acesso em: 28 de maio 2006

BORGES, M. E. N. et al. A ciência da informação discutida à luz das teorias cognitivas: estudos atuais e perspectivas para a área. Disponível em: <http://www.apbad.pt/CadernosBAD/Caderno22004/Borges+OutrosBAD2 04.pdf> Acesso em: 15 maio 2007.

BORGES, Mônica Erichsen Nassif, et al. Estudos Cognitivos em Ciência da Informação. Encontros Bibli: Revista Eletrônica de Biblioteconomia e Ciência da Informação. Florianópolis, n. 15, $1^{\circ}$ sem. 2003. Disponível em: $<$ http://www.encontros-

bibli.ufsc.br/Edicao_15/borges_estudoscognitivos.pdf >. Acesso em: 15 maio 2007.

BRANIN, J. Institutional Repositories. In: ENCYCLOPEDIA OF LIBRARY AND INFORMATION SCIENC. Londres: Taylor; Francis, 2008, p. 1-12. DOI: 10.1081/E-ELIS-120020335, 2004.

CARVALHO, Marcelo R. C. Gestão do conhecimento na implantação de processos de gestão da tecnologia da informação. 145 f. Dissertação (Mestrado em Gestão do Conhecimento e da Tecnologia de Informação). Universidade Católica de Brasília, Brasília, 2005.

COSTA, S. M. S.; LEITE, F. C. L. Repositórios institucionais: potencial para maximizar o acesso e o impacto da pesquisa em universidades. In: CONFERÊNCIA IBEROAMERICANA DE PUBLICAÇÕES ELETRÔNICAS NO CONTEXTO DA COMUNICAÇÃO CIENTÍFICA, 1. Brasília, 25 a 28 de abril de 2006. Anais... Brasília, Universidade de Brasília 2006.

CAVALCANTI, M.; GOMES, E.; PEREIRA, A. Gestão de empresas na sociedade do conhecimento. São Paulo: Campus, 2001. 168 p.

CHOO, Chun. W. A organização do conhecimento: como as organizações usam a informação para criar significado, construir conhecimento e tomar decisões. 2. ed. São Paulo: SENAC, 2006. 425 p.

DAVENPORT, Thomas H.; MARCHAND, Donald. A. A GC é apenas uma boa gestão da informação? In: DAVENPORT, T. H.; MARCHAND, D.; DICKSON, 
T. Dominando a gestão da informação. Porto Alegre: Bookman, 2004. p. 189-194.

DAVENPORT, T. H.; PRUSAK, L. Conhecimento empresarial. Rio de Janeiro: Campus, 1998. 256 p.

DEL TIO, A. L. Gestão do conhecimento aplicado ao planejamento estratégico em instituições de ensino superior. 2006. 102 f. Dissertação (Mestrado em Ciência da Informação) - Pontifícia Universidade Católica de Campinas, Centro de Ciências Humanas e Sociais Aplicadas, Programa de Pós-Graduação em Ciência da Informação. Campinas, 2006.

DIB, S. F.; SILVA, N. C. Unidade de negócio em informação - UNINF: o futuro das bibliotecas universitárias na sociedade do conhecimento. Perspectivas em Ci. Inf., Belo Horizonte, v.11, p. 20-31, jan/abr. 2006. Disponível em: <http://www.scielo.br/pdf/pci/v11n1/v11n1a03.pdf>. Acesso em: 22 de maio 2007.

DRAKE, Miriam A. Institutional repositories: hidden treasures. Searcher Magazine, v. 12, n. 5, May 2004. Disponível em: <http://www.infotoday.com/searcher/may04/drake.shtml>. Acesso em: 18 maio 2007.

DRUCKER, Peter F. "O Advento da Nova Organização". (1988). In: Knowledge Management. Harvard Business Review. Ed. Campus 2.000.

FIALHO, Francisco A. P. Ciências da cognição. Florianópolis/SC: [s.n.], 2007. No prelo.

INGWERSEN, P. Information retrieval interaction. London: Taylor Graham, 1992.

JACOB, Elin, K., SHAW, Debora. Sociocognitive perspectives on representation. Annual Review of Information Science and Technology, v. 33, p. 131-185, 1998.

JOHNSON, R. K. Partnering with faculty to enhance scholarly communication. D-Lib Magazine, v. 8, n. 11, nov. 2002. Disponível em: <http://www.dlib.org/dlib/november02/johnson/11johnson.html>. Acesso em: 28 maio 2007.

LAWRENCE, S. Free online availability substantially increases a paper's impact. NATURE webdebate. 2003. Disponível em: http://www.nature.com/nature/debates/e-access/Articles/lawrence.html>. Acesso em: 08 maio 2007.

LEITÃO, J. S. S. Estratégias para facilitar o compartilhamento de conhecimentos em uma organização de pesquisa e desenvolvimento. 110f. Tese (Doutorado em Engenharia de Produção) - Programa de PósGraduação em Engenharia de Produção, Universidade Federal de Santa Catarina, Florianópolis, 2006. 
LEITE, Fernando César Lima. Gestão do conhecimento científico no contexto acadêmico: proposta de um modelo conceitual. Universidade de Brasília, 2006. 159 f. Dissertação (Mestrado em Ciência da Informação). Universidade de Brasília, 2006.

LEITE, Fernando C.; COSTA, S. M. S. Repositórios institucionais como ferramenta de gestão do conhecimento científico no ambiente acadêmico. Perspectivas em Ci. Inf., v. 11, p. 206-219, 2006. Disponível em: <http://www.scielo.br/pdf/pci/v11n2/v11n2a05.pdf>. Acesso em: 22 maio 2007.

LIMA, Gercina A. B. Interfaces entre ciência da informação e ciência cognitiva. Ci. Inf., v. 32, n. 1, p.77-87, jan./abr. 2003. Disponível em: <http://www.ibict.br/cienciadainformacao/viewarticle. php?id=166\&layout =abstract $>$. Acesso em: 22 maio 2007.

LYNCH, C. A. Institutional repositories: essential infrastructure for scholarship in the digital age. Association Research Libraries - ARL, $\mathrm{n}$. 226, $\mathrm{p}$ 1-7, Feb. 2003. Disponível em: <http://www.arl.org/resources/pubs/br/br226/br226ir.shtml>. Acesso em: 08 maio 2007.

MCLENDON, W. Institucional repositories. Scholarly Communications in a Digital World. $2005 . \quad$ Jan. Disponível em: <http://www.unc.edu/scholcomdig/whitepapers/index.html>. Acesso em: 22 maio 2007.

NEVES, D. A. Information science and human cognition: an information processing approach. Ci. Inf., v. 35, n.1, p. 39-44, 2006. Disponível em: $<$ http://www.scielo.br/scielo.php?pid=S0100-

19652006000100005\&script=sci_arttext>. Acesso em: 22 maio 2007.

NONAKA, I; TAKEUCHI, H. Criação de conhecimento na empresa: como as empresas japonesas geram a dinâmica da inovação. Rio de Janeiro: Campus, 1997. $376 \mathrm{p}$.

REENEN, J. V. Open access and connectedness: stimulating unexpected innovation through the use of institutional open archives. Ci. Inf., v. 35, n. 2, p. 17-26, 2006. Disponível em: <http://www.scielo.br/pdf/ci/v35n2/a03v35n2.pdf>. Acesso em: 22 maio 2007.

RICHARD, Jean-François. Les ativités mentales: comprendre, raisonner, trouver des

solutions. Paris: Armand Colin, 1998. 381p.

RODRIGUES, Eloy. Promovendo o acesso livre à literatura científica: o RepositóriUM e a Política de Auto-Arquivo da Universidade do Minho. In: ENCONTRO SOBRE REPOSITÓRIOS INSTITUCIONAIS, Leiria, Portugual, 9 de maio de 2007. Anais... Portugal: Instituto Politécnico de Leiria, 2007.

SVEIBY, K. E. A nova riqueza das organizações: gerenciando e avaliando patrimônios de conhecimento. Rio de Janeiro: Campus, 1998. 260 p. 